\title{
The effect of fatty acid surfactants on the uptake of ozone to aqueous halogenide particles
}

\author{
A. Rouvière and M. Ammann \\ Laboratory for Radio and Environmental Chemistry, Paul Scherrer Institut, 5232 Villigen, Switzerland
}

Received: 8 June 2010 - Published in Atmos. Chem. Phys. Discuss.: 21 June 2010

Revised: 26 October 2010 - Accepted: 23 November 2010 - Published: 3 December 2010

\begin{abstract}
The reactive uptake of ozone to deliquesced potassium iodide aerosol particles coated with linear saturated fatty acids $\left(\mathrm{C}_{9}, \mathrm{C}_{12}, \mathrm{C}_{15}, \mathrm{C}_{18}\right.$ and $\left.\mathrm{C}_{20}\right)$ was studied. The experiments were performed in an aerosol flow tube at 293 $\mathrm{K}$ and atmospheric pressure. The uptake coefficient on pure deliquesced KI aerosol was $\gamma=(1.10 \pm 0.20) \times 10^{-2}$ at $72-$ $75 \%$ relative humidity. In presence of organic coatings, the uptake coefficient decreased significantly for long straight chain surfactants $\left(\geq C_{15}\right)$, while it was only slightly reduced for the short ones $\left(\mathrm{C}_{9}, \mathrm{C}_{12}\right)$. We linked the kinetic results to the monolayer properties of the surfactants, and specifically to the expected phase state of the monolayer formed (liquid expanded or liquid condensed state). The results showed a decrease of the uptake coefficient by $30 \%$ for $\mathrm{C}_{12}, 85 \%$ for $\mathrm{C}_{15}$ and $50 \%$ for $\mathrm{C}_{18}$ in presence of a monolayer of a fatty acid at the equilibrium spreading pressure at the air/water interface. The variation among $\mathrm{C}_{12}, \mathrm{C}_{15}$ and $\mathrm{C}_{18}$ follows the density of the monolayer at equilibrium spreading pressure, which is highest for the $\mathrm{C}_{15}$ fatty acid. We also investigated the effect of organic films to mixed deliquesced aerosol composed of a variable mixture of $\mathrm{KI}$ and $\mathrm{NaCl}$, which allowed determining the resistance exerted to $\mathrm{O}_{3}$ at the aqueous surface by the two longer chained surfactants pentadecanoic acid $\left(\mathrm{C}_{15}\right)$ and stearic acid $\left(\mathrm{C}_{18}\right)$. For these, the probability that a molecule hitting the surface is actually transferred to the aqueous phase underneath was $\beta_{\mathrm{C}_{15}}=6.8 \times 10^{-4}$ and $\beta_{\mathrm{C}_{18}}=3.3 \times 10^{-4}$, respectively. Finally, the effect of twocomponent coatings, consisting of a mixture of long and short chained surfactants, was studied qualitatively.
\end{abstract}

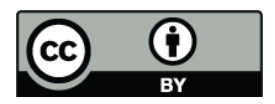

Correspondence to: M. Ammann (markus.ammann@psi.ch)

\section{Introduction}

Atmospheric aerosols contain a complex mixture of inorganic and organic compounds. It has been determined that organic species represent a significant percentage (20-90\%) of the total mass fraction of the submicron aerosol varying with source and location (Zhang et al., 2007; Day et al., 2009; Kanakidou et al., 2004; O’Dowd et al., 2004; Putaud et al., 2004).

Fatty acids come from both anthropogenic (cooking, combustion, traffic emission) and biogenic sources (forests, plants, marine biota, biomass burning) (Cheng et al., 2004; Hou et al., 2006; Huang et al., 2006; Pio et al., 2001; Robinson et al., 2006; Schauer et al., 2001; Simoneit and Mazurek, 2007). They are known to act as surfactants in the atmosphere (Rudich, 2003; Ellison et al., 1999; Gill et al., 1983). Especially the $\mathrm{C}_{12}-\mathrm{C}_{19}$ straight chain fatty acids contribute contribute significantly to the organic coating of sea salt particles (Cavalli et al., 2004; Mochida et al., 2002, 2007; Tervahattu et al., 2002a, b, 2005). Tervahattu et al. (2002), have provided evidence that fatty acids are actually located at the surface of sea salt particles. We note, however, that fatty acids form only part of organic matter found in marine aerosol, which consists of a wide range of carbohydrates, protein residues, lipids (Facchini et al., 2008; Aller et al., 2005; Kuznetsova et al., 2005; Leck and Bigg, 2005; O'Dowd et al., 2004).

Recently, several studies have focused on the influence of organic surfactant films at the air/water interface in order to determine their impact on atmospheric chemistry (Donaldson and Vaida, 2006; Smoydzin and von Glasow, 2007; Gilman et al., 2006). It turns out that an important aspect of organic coatings may be that they reduce the mass transfer between the gas and particle phases. Organic coatings on aqueous aerosol particles can also affect the process of CCN formation and growth (Andrews and Larson, 1993; Chuang, 2003; Chan and Chan, 2005). In view of its importance to

Published by Copernicus Publications on behalf of the European Geosciences Union. 
the ozone and halogen budgets in the marine boundary layer, several studies have focused on the reactive uptake of $\mathrm{N}_{2} \mathrm{O}_{5}$ and have shown a decrease of the reactive uptake of $\mathrm{N}_{2} \mathrm{O}_{5}$ in presence of monolayers surfactants (Badger et al., 2006; Cosman and Bertram, 2008; Cosman et al., 2008; Knopf et al., 2007; McNeill et al., 2006; McNeill et al., 2007; Park et al., 2007; Riemer et al., 2009; Stewart et al., 2004). For example Thornton and Abbatt (2005) demonstrated that the presence of a monolayer of hexanoic acid inhibits $\mathrm{N}_{2} \mathrm{O}_{5}$ uptake by a factor of 3 to 4 on deliquesced sea salt aerosol. McNeill et al (2006) found that the presence of sodium dodecyl sulfate (SDS) decreases the $\mathrm{N}_{2} \mathrm{O}_{5}$ reaction probability on deliquesced $\mathrm{NaCl}$ particles. Stemmler et al. (2008) studied the effect of surfactants on the uptake of nitric acid $\mathrm{HNO}_{3}$ to deliquesced $\mathrm{NaCl}$ aerosol. They showed that the uptake coefficient was reduced by a factor of 5-50 when the aerosol was coated with fatty acids. The effect was most pronounced with pentadecanoic acid and stearic acid, which they ascribed to the ability of these fatty acids to spontaneously form relatively well ordered, dense films. This indicates the importance of the surface phase state of surfactants in determining the phase transfer properties, an observation also made in conjunction with $\mathrm{N}_{2} \mathrm{O}_{5}$ uptake (Bertram and Thornton, 2009; Knopf et al., 2007) and with acetic acid uptake (Gilman and Vaida, 2006).

However organic coatings can also promote the phase transfer. Experiments by Glass et al. (2006), Burden et al. (2009) and Park et al. (2009) have shown that soluble surfactants such as butanol or hexanol can enhance the uptake of $\mathrm{HCl}$ into sulfuric acid through specific interactions of the alcohol head groups with chloride ions. Many uncertainties remain with respect to the structure and the phase state of surfactant films on atmospheric particles and the changes to the properties of the aqueous surface and to what degree these properties affect the transfer of trace gases from the gas to the liquid phase. One way to explore these is to extend the range of gas molecules to a less soluble species, one of the motivations to study the reactive uptake of ozone to deliquesced $\mathrm{KI}$ and mixed $\mathrm{NaCl} / \mathrm{KI}$ particles coated with fatty acids.

So far, the effect of surfactant layers on the phase transfer of $\mathrm{O}_{3}$ to deliquesced aerosols has not been investigated. Recently, the heterogeneous reaction of ozone with aqueous iodide has been studied in presence of aqueous organic species such as phenols (Hayase et al., 2010), where, however, phenols interacted with ozone as a competing reactant rather than as inhibitor of phase transfer. Studies of ozone reacting with oleate covered deliquesced $\mathrm{NaCl}$ particles (McNeill et al., 2007) were related to the reaction with the double bond at the surface in contrast to similar studies with pure oleic particles (Smith et al., 2002; Zahardis and Petrucci, 2007) and not of direct relevance to the present investigation focusing on the transfer across a layer of saturated fatty acids. Recently, we studied the reactive uptake of $\mathrm{O}_{3}$ to deliquesced potassium iodide and mixed sodium chloride/potassium io- dide aerosol particles (Rouvière et al., 2010). From these results, we obtained an average initial uptake coefficient of $\gamma$ $=(1.10 \pm 0.20) \times 10^{-2}$ and a bulk accommodation coefficient of $\alpha_{\mathrm{b}}=0.6 \pm_{0.5}^{0.4}$. Iodide provides a substantial aqueous phase sink to drive uptake of ozone and is thus ideally suited for the present investigation. This reaction is also important in halogen activation processes of the marine boundary layer, as it may initiate halogen activation (Enami et al., 2008). Of some relevance to the present study is the fact that surfactants may affect the interfacial distribution of halogenide ions near the interface (Tobias and Hemminger, 2008; Krisch et al., 2007; Latif and Brimblecombe, 2004).

Even though the fatty acids chosen for the present study do not represent the breadth of organic species present in marine aerosol, they form reasonably well characterized monolayers with predictable properties (Seidl, 2000, and references therein). Once in contact with an aqueous solution, they readily spread over the solution air interface with spreading rates in the seconds range for spatial scales of submicron particles (Tabazadeh, 2005). Therefore, they form an ideal model system for the present investigation.

\section{Experimental section}

A schematic representation of the experimental setup is given in Fig. 1, which has been described in detail by Rouvière et al. (2010). Potassium iodide particles were produced by nebulising an aqueous solution containing $5 \mathrm{~g} / \mathrm{L}$ of potassium iodide salt into $5 \mathrm{~L} / \mathrm{min}$ dry $\mathrm{N}_{2}$. The aerosol particles emitted were dried in a silica gel diffusion dryer, exposed to a bipolar ion source $\left({ }^{85} \mathrm{Kr}\right)$ to obtain an equilibrium charge distribution and then passed through an electrostatic precipitator to remove all charged particles. For hygroscopic characterization experiments and to quantify the amount of fatty acid condensed on the particles (see below), a first DMA (Differential Mobility Analyzer) could be placed after the ion source to obtain a monodispersed aerosol. $\mathrm{O}_{3}$ uptake experiments were performed with the polydispersed aerosol without this DMA in line, since the surface area and liquid volume of the monodispersed aerosol would not be enough to lead to appreciable ozone losses in the reactor. The aerosol was humidified to $75 \% \mathrm{RH}$ (above the deliquescence humidity of KI of $67 \%$; Woods et al., 2007). After humidification, KI particles passed through an equilibrium reactor to allow the particles to grow (residence time about $1 \mathrm{~min}$ ). A growth factor of 1.3 was obtained in absence of coating (Rouvière et al, 2010) at the same RH, which proves that the particles were deliquesced. Under the conditions of the present experiments thus a pure aqueous KI aerosol contained around 7.3 M KI. Ozone was generated by irradiating a flow of a mixture of $\mathrm{O}_{2}$ and $\mathrm{N}_{2}$ in a quartz tube with an ultra-violet lamp (PenRay 3SC-9, UV Products Ltd., USA), which has a resonance line at a wavelength of $185 \mathrm{~nm}$. Then the $\mathrm{O}_{3} / \mathrm{O}_{2} / \mathrm{N}_{2}$ flow was introduced to the aerosol flow tube through a movable 


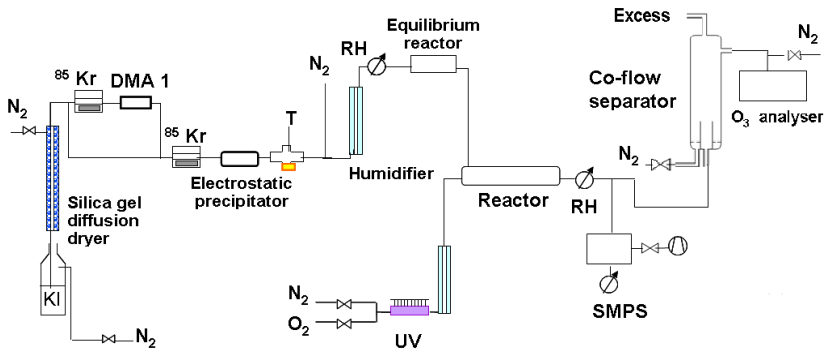

Fig. 1. Overview of the experimental setup.

injector and diluted by the aerosol flow or $\mathrm{N}_{2}$ (ratio 1/1). In absence of particles, the ozone concentration in the reactor was normally $90 \mathrm{ppb}$. The aerosol flow tube reactor was a pyrex tube, $85 \mathrm{~cm}$ long, with an inner diameter of $2.5 \mathrm{~cm}$. The ozone injector, which was kept in the center of the flow tube by means of three PFA legs, could be moved to vary the reaction time from 2 to $25 \mathrm{~s}$ to obtain kinetic information. After the reactor, the aerosol surface concentration was measured with a Scanning Mobility Particle Sizer (SMPS) consisting of a DMA (3071, TSI) and a condensation particle counter (CPC, 3022, TSI, USA) collecting the aerosols at the exit of the flow tube. Typical particle number, surface and mass concentrations of the polydispersed aerosol in absence of fatty acids were $5 \times 10^{5}$ particles $/ \mathrm{cm}^{3}, 1.6 \times 10^{-4} \mathrm{~cm}^{2} / \mathrm{cm}^{3}$, and $1000 \mu \mathrm{g} / \mathrm{m}^{3}$, respectively. The concentration of ozone was measured with a photometric ozone analyzer (model ML 9810, Monitor Labs Inc, USA) after separating ozone from the particles by diffusion in an annular coflow device. This separation was necessary, because the aerosol interferes with the photometric ozone detection due to scattering and absorption (see Rouvière et al., 2010, for more details).

In order to investigate the effects of the surfactants on the ozone uptake, varying amounts of a specific fatty acid were condensed on the dry particles. Straight chain $\mathrm{C}_{9}-\mathrm{C}_{20}$ fatty acids (FA) were used in the experiments. The effectiveness of the surfactant coatings will be related to their properties, as provided in Gabler and Heumann (1993). The procedure to get a reproducible amount of fatty acid on the particles has already been described by Stemmler et al. (2008). An organic vapor was generated by heating $0.5 \mathrm{~g}$ of surfactant in a temperature controlled reservoir. The coating took place after removing charged particles from the aerosol flow and before their humidification (Fig. 1). The aerosol flow passed over the reservoir through the heated zone and thereby got into contact with the surfactant vapor. In the condenser tube downstream of the warm zone, the gas gradually cooled and the vapor condensed onto the surface of the particles. The amount of fatty acid condensed on the particles was controlled by changing the evaporator temperature. In order to calibrate the size change with evaporator temperature, we switched the additional DMA mentioned above into the aerosol flow to obtain monodispersed particles. For the ex-
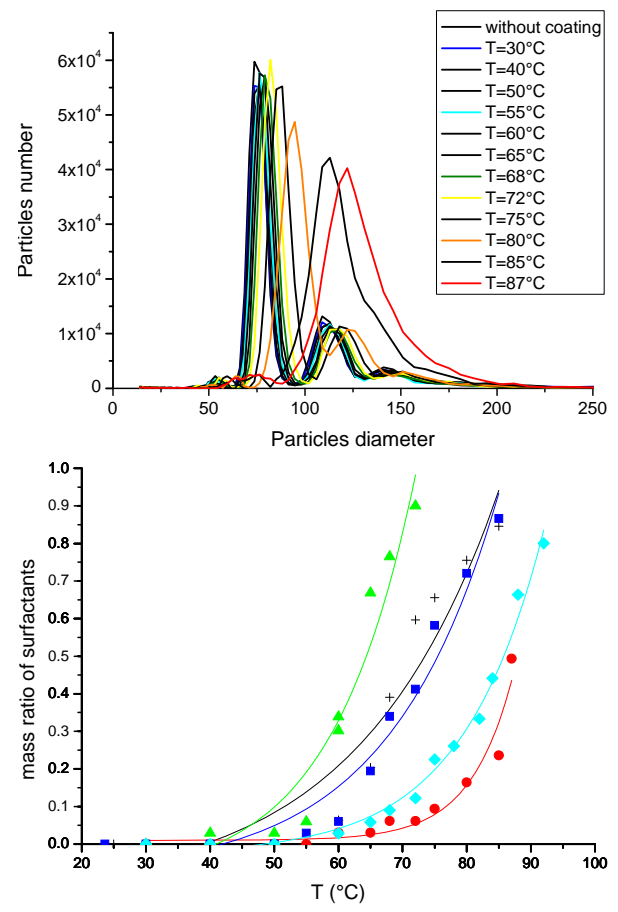

Fig. 2. (a) Particle size distributions of a monodisperse dry aerosol (KI) exposed to lauric acid $\left(\mathrm{C}_{12}\right)$ in the evaporator at different temperatures. (b) Evolution of the mass ratio of surfactants as a function of the evaporator temperature (black crosses: $\mathrm{C}_{9}$, red circles: $\mathrm{C}_{12}$, green triangles: $\mathrm{C}_{15}$, blue squares: $\mathrm{C}_{18}$ and turquoise diamonds: C20). The solid lines are only guides to the eye.

ample of lauric acid, Fig. 2a demonstrates the increasing particle size of monodispersed KI particles (selected at the mode diameter of the polydispersed particle size spectrum) coated with increasing amounts of lauric acid $\left(\mathrm{C}_{12}\right)$ with increasing evaporator temperature. Since the particles were charged to equilibrium with the bipolar ion source, there was always a fraction of doubly and triply charged particles, which appear as separate modes after subsequent neutralization and separation with the second DMA. This is not of further importance, since we only used these measurements to obtain the diameter change due to the organic added. We used the main mode for this analysis only. The mass ratio of surfactant was derived from the associated change in particle volume for each temperature. The volume of fatty acid $\left(V_{\mathrm{FA}}\right)$ was obtained from the difference of the volume of coated particles $\left(V_{\mathrm{KI}+\mathrm{FA}}\right)$ calculated from the corresponding measured diameter $\left(D_{\mathrm{c}}\right)$ and the volume of the dry particles with diameter $D_{0}\left(V_{\mathrm{KI}}\right)$. Using the densities of KI and the fatty acid of interest, respectively, we determined the mass ratio of fatty acid $\left(m_{\mathrm{FA}}\right) /\left(m_{\mathrm{FA}}+m_{\mathrm{KI}}\right)$. The procedure with the monodispersed aerosol was only used to calibrate the size change with evaporator temperature more precisely than with the polydisperse aerosol. For the larger organic mass ratios, we could confirm that the size changes due to the coating measured with the 
polydispersed aerosol were always consistent with the more precise calibration using monodispersed particles.

The mass ratios obtained for $\mathrm{C}_{9}, \mathrm{C}_{12}, \mathrm{C}_{15}, \mathrm{C}_{18}$ and $\mathrm{C}_{20}$ as a function of the temperature of the evaporator are shown in Fig. 2b. We do not know whether the organics formed a homogeneous coating on the dry particles or condensed as a separate droplet or crystal attached to the particle. We therefore associate a significant uncertainty with these values, as we do not take into account any shape effects. It serves reasonably well to compare among the different fatty acids.

Once the particles were coated they were passing through the humidifier and the equilibration reactor to allow them to deliquesce and the organic monolayers to develop. The experimental procedure of the uptake experiments always involved first measuring the size distribution of the dry uncoated particles, then that of the dry coated and finally that of the coated deliquesced particles as they exited the flow reactor. This allowed routinely checking the diameter growth due to the humidity change, which was always consistent with the growth observed in absence of fatty acids. Once a fatty acid (liquid for $\mathrm{C}_{9}$ or solid otherwise) is in contact with the aqueous phase after deliquescence, fatty acid molecules start to dissolve from its bulk into the surface and spread into a monolayer. Aumann and Tabazadeh (2008) report direct measurements of the spreading rates of crystalline stearic acid over different solutions at room temperature and have shown that spreading times over the scales of submicron particles are at maximum of the order of a few seconds. In a few own qualitative experiments with bulk solutions in a petri dish comparable to those by Aumann and Tabazadeh (2008), we have observed that the $C_{12}$ and $C_{15}$ fatty acids spread even faster than the $\mathrm{C}_{18}$. Therefore, the residence time of one minute in our equilibration reactor safely allowed the monolayers to spread to form a layer on the particle with homogeneous density. In presence of an excess of the fatty acid, the density increases until the so called equilibrium spreading pressure (see below) is reached, eventually passing through a phase transition before that. The excess remains as is or may also restructure into a lens on the surface. The only assertions we are making are that the fatty acids homogeneously spread over the deliquesced particle, and, in presence of an excess of fatty acid, the monolayer reaches the density corresponding to the equilibrium spreading pressure with a separate bulk phase remaining attached to the droplet.

\section{Assessment of monolayer properties}

The monolayer properties of the fatty acids of interest here were explored using the model developed by Seidl (2000). These monomolecular films can exist in three different states: gaseous, expanded and condensed liquid state. The corresponding $\pi$-A isotherms are shown in Fig. 3a, where the film pressure is represented as a function of the area per molecule. This figure indicates also two essential values for
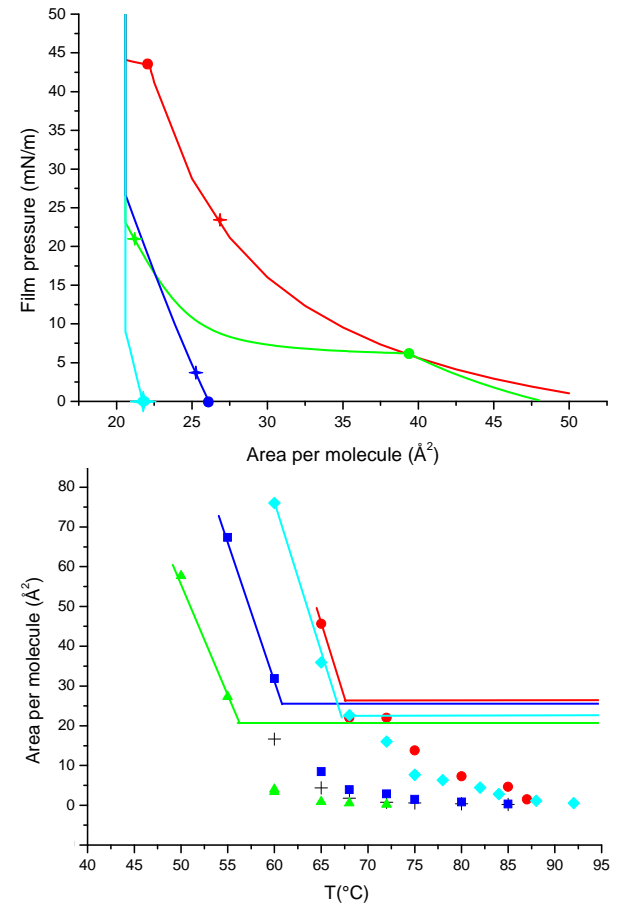

Fig. 3. (a). $\pi$-A isotherms of lauric acid (red line), pentadecanoic acid (green line), stearic acid (blue line) and arachidic acid (turquoise line), according to the model of Seidl (2000). The crosses represent the Equilibrium spreading Pressure of an excess bulk phase of the individual fatty acids and the circles illustrate the phase transition film pressure between the expanded and condensed phases. (b). Area per molecule of the fatty acids as a function of the evaporator temperature (black crosses: $\mathrm{C}_{9}$, red circles: $\mathrm{C}_{12}$, green triangles: $\mathrm{C}_{15}$, blue squares: $\mathrm{C}_{18}$ and turquoise diamonds: $\mathrm{C}_{20}$ ) as calculated from the particle growth measurements. The solid lines indicate the expected behavior of the true area per molecule to take into account that the monolayers cannot spontaneously get more compressed than the equilibrium spreading pressure.

the $\pi$-A isotherms that are the location of the phase transition from the expanded to the condensed liquid phase state ( $\mathrm{Fj}$, expressed as the film pressure, where the phase transition occurs) and the Equilibrium Spreading Pressure (ESP). The ESP is defined as the pressure of the film in equilibrium with its bulk phase. It may be compared to the solubility of a compound in solution as the 3-D analogue in that if more of this compound is available than given by the solubility and the volume of solution, the excess salt remains as a bulk phase in equilibrium with the solution. Compounds exhibiting an $\mathrm{ESP}>\mathrm{mN} / \mathrm{m}$ spread spontaneously over the aqueous surface. Data concerning Fj and ESP are also reported in Table 1. We assume that if we have deposited fatty acids in amounts more than the equivalent of the corresponding monolayer at the ESP on the wet particles, the phase state of this monolayer is given by the ESP, while the rest remains as excess solid or liquid fatty acid attached to the aqueous 
Table 1. Properties of the surfactants.

\begin{tabular}{llllllrrr}
\hline Name & Formula & $\begin{array}{l}\text { Molecular } \\
\text { weight } \\
\mathrm{g} / \mathrm{mol}\end{array}$ & $\begin{array}{l}\text { Density } \\
\mathrm{g} / \mathrm{cm}^{3}\end{array}$ & $\begin{array}{l}\text { Aqueous } \\
\text { solubility g/100 g } \\
\text { of water at } 20^{\circ} \mathrm{C}\end{array}$ & $\begin{array}{l}\text { Melting point } \\
{ }^{\circ} \mathrm{C}\end{array}$ & $\begin{array}{l}\text { Vapor pressure } \\
\text { at } 25^{\circ} \mathrm{C}\end{array}$ & $\begin{array}{r}\text { ESP } \\
\mathrm{mN} / \mathrm{m}^{(*)}\end{array}$ \\
\hline Nonanoic acid & $\mathrm{C}_{9} \mathrm{H}_{18} \mathrm{O}_{2}$ & 158.24 & 0.900 & 0.0284 & 12.4 & $\begin{array}{r}\text { Fj } \\
\mathrm{mN} / \mathrm{m}^{(*)}\end{array}$ \\
Lauric acid & $\mathrm{C}_{12} \mathrm{H}_{24} \mathrm{O}_{2}$ & 200.32 & 0.880 & 0.0055 & 43.8 & $2.9 \times 10^{-3}$ & 23.4 & 43.5 \\
Pentadecanoic acid & $\mathrm{C}_{15} \mathrm{H}_{30} \mathrm{O}_{2}$ & 242.40 & 0.8423 & 0.0012 & 52.3 & $1.1 \times 10^{-4}$ & 21.0 \\
Stearic acid & $\mathrm{C}_{18} \mathrm{H}_{36} \mathrm{O}_{2}$ & 284.48 & 0.847 & 0.00029 & 69.3 & $5.6 \times 10^{-7}$ & 3.7 & -23.9 \\
Arachidic acid & $\mathrm{C}_{20} \mathrm{H}_{40} \mathrm{O}_{2}$ & 312.54 & 0.8240 & - & 76.5 & $4.4 . \times 10^{-8}$ & -1.6 & -57.9 \\
\hline
\end{tabular}

$\left(^{*}\right)$ ESP: Equilibrium spreading pressure; Fj: phase transition film pressure from the expanded to the condensed liquid phase state. The values were calculated from the model of Seidl (2000).

solution. With smaller amounts of a fatty acid we assume that they form a more dilute monolayer with homogeneous surface density over the particle. To make this quantitative, from the mass fractions plotted in Fig. $2 b$ we calculated the area per molecule as a function of evaporator temperature plotted in Fig. 3b. The surface density (i.e., inverse area per molecule) was calculated as the ratio of the number of fatty acid molecules per particle ( $\left.n_{\mathrm{FA}}\right)$ divided by the surface area per particle as obtained from the SMPS. Then, knowing the ESP of each FA from the corresponding $\pi$-A isotherm shown in Fig. 3a, the area per molecule in the monolayer was assumed to remain constant with further increasing mass fraction and represented as a solid line in Fig. 3b. This figure should demonstrate that for higher mass fractions, the monolayer density and structure remained constant, while the excess material formed a separate phase increasing the overall particle surface area but not affecting the monolayer properties above the aqueous solution. As already pointed out by Stemmler et al. (2008), we do not expect formation of micelles for these fatty acids. We are aware that many amphiphilic organic compounds may form micelles above the so called critical micelle concentration, where monolayers at the ESP and micelles may coexist. Indeed, the conjugate base ions of the fatty acids used here could form micelles within the particles (Tabazadeh, 2005). In our experiment, we did not take any special precautions to avoid the presence of $\mathrm{CO}_{2}$ and the $\mathrm{pH}$ of the deliquesced particles was likely around 6. Since $p \mathrm{~K} a$ values of the fatty acids used in our study and for the condition, when they are at the surface of an aqueous solution, are between 7 and 10, they remain protonated (Kanicky et al., 2000; Kanicky and Shah, 2002).

\section{Results and discussion}

The effects of fatty acids to the ozone uptake on deliquesced $\mathrm{KI}$ particles or on mixed $\mathrm{NaCl} / \mathrm{KI}$ particles were investigated by directly comparing the rate of uptake of ozone to coated particles with that to uncoated particles. The rate of uptake is expressed as the uptake coefficient, $\gamma$, given by the number of gas molecules being taken up by the particles divided by the number of gas molecules impinging onto their surface (Pöschl et al., 2007). Thereby, the rate of ozone loss from the gas phase is described as a pseudo-first order process (Eq. 1), where $k_{\mathrm{g}, \mathrm{p}, \mathrm{O}_{3}}$ is the first order rate coefficient, and $t$ is the exposure time between the gas and the aerosol surface (Liu et al., 2001). Then, the rate coefficient can be related to the uptake coefficient, $\gamma$, on the aerosol using Eq. (2), where $S$ is the aerosol surface area per volume of gas $\left(\mathrm{m}^{2} / \mathrm{m}^{3}\right)$ and $\omega$ is the mean molecular velocity of $\mathrm{O}_{3}$ in the gas phase $(\mathrm{m} / \mathrm{s})$.

$$
\begin{aligned}
& -\frac{d\left[\mathrm{O}_{3}\right]}{d t}=k_{\mathrm{g}, \mathrm{p}, \mathrm{O}_{3}}\left[\mathrm{O}_{3}\right] \\
& k_{\mathrm{g}, \mathrm{p}, \mathrm{O}_{3}}=\frac{S \omega \gamma}{4}
\end{aligned}
$$

In absence of an organic coating, our previous study of uptake of ozone to deliquesced potassium iodide aerosol particles showed that the uptake was both influenced by the bulk accommodation coefficient $\left(\alpha_{\mathrm{b}}\right)$ and the bulk reactivity $\left(\Gamma_{\mathrm{b}}\right)$, leading to an initial uptake coefficient of $\gamma=(1.10 \pm 0.20) \times 10^{-2}$ (Rouvière et al., 2010).

In presence of a coating and under appropriate steady state approximations, the uptake coefficient of gas molecules from the gas-phase into a liquid can be expressed in terms of a sequence of resistances as shown in Eq. (3). In absence of an elementary picture of the detailed processes we replace the bulk accommodation coefficient, the probability that a gas phase molecule hitting the surface enters the liquid in solvated form, by an overall inverse resistance at the surface, $1 / \beta$, for transport across the surfactant layer including also transfer into the liquid. The inverse resistance due to the bulk liquid phase reaction is expressed by $1 / \Gamma_{\mathrm{b}}$. In Eq. (3), $T$ is the temperature, $H$ is the Henry's law coefficient of $\mathrm{O}_{3}, D_{\mathrm{b}, \mathrm{O}_{3}}$ is the diffusion coefficient of $\mathrm{O}_{3}$ in the liquid phase, $R$ is the universal gas constant, and $k_{\mathrm{b}}$ the second order loss rate constant of $\mathrm{O}_{3}$ in the liquid phase:

$$
\frac{1}{\gamma}=\frac{1}{\beta}+\frac{1}{\Gamma_{\mathrm{b}}} \text { with } \Gamma_{\mathrm{b}}=\frac{4 H R T \sqrt{D_{\mathrm{b}, \mathrm{O}_{3}} k_{\mathrm{b}}\left[I^{-}\right]}}{\omega}
$$




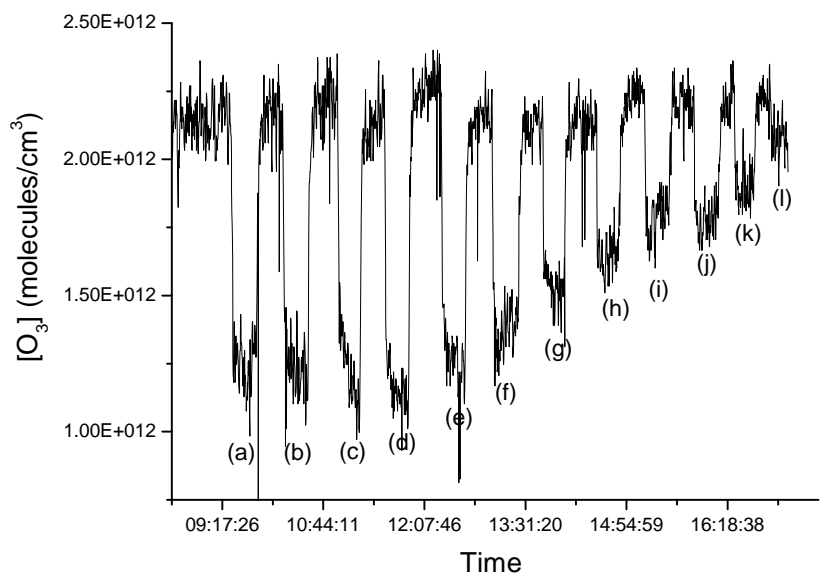

Fig. 4. Experimental profile of the $\mathrm{O}_{3}$ concentration in presence of lauric acid $\left(\mathrm{C}_{12}\right)$ for different coating temperatures in the evaporator ((a) without coating, (b) $T=23.6^{\circ} \mathrm{C}$, (c) $T=30^{\circ} \mathrm{C}$, (d) $T=40^{\circ} \mathrm{C}$, (e) $T=50^{\circ} \mathrm{C}$, (f) $T=60^{\circ} \mathrm{C}$, (g) $T=65^{\circ} \mathrm{C}$, (h) $T=68^{\circ} \mathrm{C}$, (i) $T=$ $72^{\circ} \mathrm{C}$, (j) $T=75^{\circ} \mathrm{C}$, (k) $T=80^{\circ} \mathrm{C}$, (l) $T=90^{\circ} \mathrm{C}$ ).

Note that in our previous study (Rouvière et al., 2010) we explicitly kept track of the iodide content as a function of reaction time to take into account its significant depletion, depending on particle size, during the residence time in the flow reactor and the coflow device. In the present study we used a simplified first order treatment as the coated particle exhibited significantly less ozone uptake, so that iodide in the aerosol phase remained in excess. After having established first order conditions for a number of representative cases, the reactive uptake coefficients were determined from the removal of $\mathrm{O}_{3}$ at a fixed maximum interaction time (41s, including the residence time in the coflow device) as a function of the amount of fatty acid deposited at the particle surface, which was related to the temperature in the evaporator as mentioned above. This allowed to directly compare uptake to coated particles with that to uncoated particles and reduced the uncertainties related to day to day variations in flows, humidity and aerosol properties. The initial concentration of $\mathrm{O}_{3}$ in absence of particles was around $2.2 \times 10^{12}$ molecules $/ \mathrm{cm}^{3}$. A typical decay of ozone after admission of deliquesced coated particles in the reactor is shown in Fig. 4 as a function of the evaporator temperature for the example of lauric acid $\left(\mathrm{C}_{12}\right)$. The ozone signal returned to its initial value within about 2 min after exchanging the particle laden flow with a flow of pure $\mathrm{N}_{2}$, consistent with the residence time distribution of the particles in the flow tube and the coflow separation device, and the response time of the $\mathrm{O}_{3}$ analyzer. Evidently, the ozone depletion was decreasing with increasing amounts of lauric acid.

Uptake coefficients of ozone to deliquesced potassium iodide coated by several fatty acids $\left(\mathrm{C}_{9}, \mathrm{C}_{12}, \mathrm{C}_{15}, \mathrm{C}_{18}\right.$ and $\left.\mathrm{C}_{20}\right)$ were measured. Figure 5 a shows the ratio $\left(\gamma_{\text {coated }} / \gamma_{\text {coated }}\right)$ of the uptake coefficient to coated particles to that of neat del-
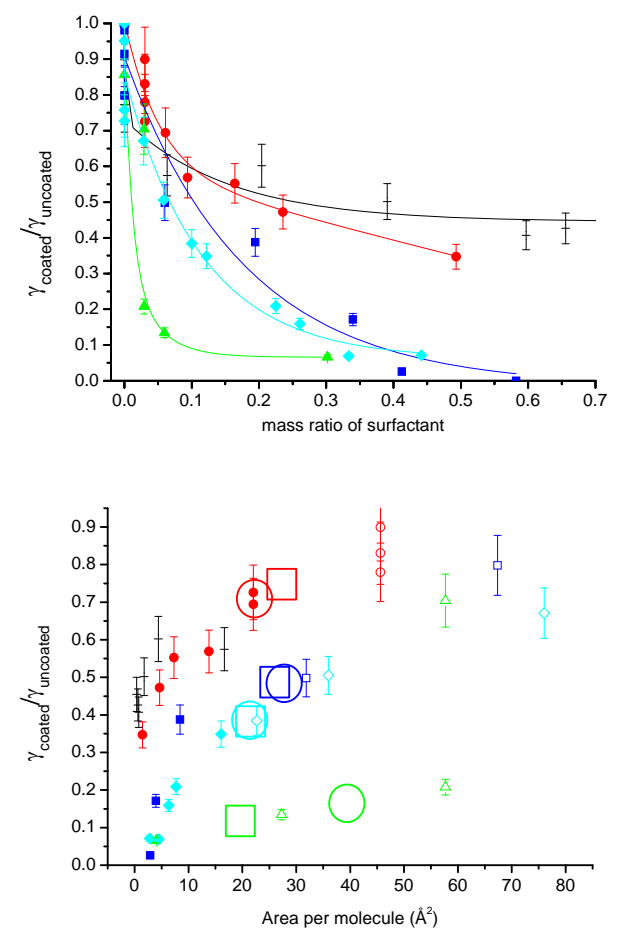

Fig. 5. (a) Ratio of the uptake coefficient for coated particles to that for uncoated particles $\left(\gamma_{\text {coated }} / \gamma_{\text {uncoated }}\right)$ containing dry mass ratios of $0-70 \%$ of surfactant for different fatty acids (black crosses: $\mathrm{C}_{9}$, red circles: $\mathrm{C}_{12}$, green triangles: $\mathrm{C}_{15}$, blue squares: $\mathrm{C}_{18}$ and turquoise diamonds: $\mathrm{C}_{20}$ ). The lines are only guides to the eye. (b) Ratio $\gamma_{\text {coated }} / \gamma_{\text {uncoated }}$ as a function of the area per molecule of surfactant (black crosses: $\mathrm{C}_{9}$, red circles: $\mathrm{C}_{12}$, green triangles: $\mathrm{C}_{15}$, blue squares: $\mathrm{C}_{18}$ and turquoise diamonds: $\mathrm{C}_{20}$ ). The rectangles represent the position of the equilibrium spreading pressure ESP and the circles represent the phase transition film pressure $\mathrm{Fj}$. For each fatty acid, the open symbols denote data points, where the monolayer has a density smaller than expected at ESP, while plain symbols denote datapoints beyond the ESP, where the additional fatty acid mass was remaining as a separate bulk phase.

iquesced KI particles, covering the range of mass ratios of $0-70 \%$ of surfactants. For $\mathrm{C}_{9}$ and $\mathrm{C}_{12}$, the changes were relatively weak, with $\gamma_{\text {coated }} / \gamma_{\text {coated }}$ dropping to about $50 \%$. For the $\mathrm{C}_{9}$ acid, which exhibits the highest water solubility among the fatty acids used in the present investigation, less than $1 \%$ of the number of molecules in a monolayer at ESP could be dissolved in a pure aqueous particle of the size as used in our experiments. For $\mathrm{C}_{9}$, we may also suspect some losses due to evaporation as already discussed by Stemmler et al. (2008). However, as presented in detail below, it is more likely the monolayer properties that determine the higher permeability of the $\mathrm{C}_{9}$ and $\mathrm{C}_{12}$ films. The saturated $\mathrm{C}_{15}, \mathrm{C}_{18}$ and $\mathrm{C}_{20}$ acids lead to a strong depletion of the reaction rate of $\mathrm{O}_{3}$ with aqueous KI particles. Overall, it appears that there is a trend of increasing degree of reduction in $\gamma$ with the length of the hydrocarbon chain, although there is an exception with 
the $\mathrm{C}_{15}$. Therefore, the first apparent conclusion is that also for $\mathrm{O}_{3}$ organic surfactant coatings can have significant effects on interfacial mass transfer, similar to other species, such as $\mathrm{N}_{2} \mathrm{O}_{5}$ or $\mathrm{HNO}_{3}$. Another way to interpret these results and to relate them to the monolayer properties is to plot the ratio $\gamma_{\text {coated }} / \gamma_{\text {coated }}$ as a function of the area per molecule of surfactant as shown in Fig. 5b. On this scale, the low evaporator temperatures that led to low surfactant mass ratios plot at the high area per molecule end, i.e., the area per molecule decreases with increasing mass ratio for all fatty acids $\mathrm{C}_{9}-\mathrm{C}_{20}$. We reiterate the assessment of the monolayer properties as above. Once the calculated area per molecule is lower than the position of the ESP in the phase diagram, i.e., at mass ratios high enough to leave an excess of bulk fatty acid, the calculated areas per molecule do not make sense, but just result from normalizing the number of fatty acid molecules by the surface area. This is expressed in Fig. $5 b$ by using plain, rather than open symbols for data points beyond the ESP. Beyond the ESP, the area per molecule in the monolayer does not decrease further, since no external force is applied for further compression, as already indicated by the lines shown in Fig. 3b. The excess surfactant molecules remain as a separate bulk phase as discussed above. ESP data were only available for $\mathrm{C}_{12}$ to $\mathrm{C}_{20}$. From that we can deduce a decrease of the uptake coefficient by $30 \%$ for $\mathrm{C}_{12}, 85 \%$ for $\mathrm{C}_{15}$ and $50 \%$ for $\mathrm{C}_{18}$ in presence of a monolayer of a fatty acid at the ESP at the air/water interface. We note that the further decrease of $\gamma_{\text {coated }} / \gamma_{\text {coated }}$ with increasing mass ratio is not due to further compression of the monolayer (since there is no driving force for that) but rather due to the extension of the separate fatty acid phase. At high mass ratios, the compound particle may be dominated by the fatty acid phase in volume and surface area, and only the aqueous subphase with the monolayer at ESP contributes to $\mathrm{O}_{3}$ uptake. If for the $\mathrm{C}_{18}$ fatty acid at $20 \%$ mass ratio we consider that the excess of fatty acid formed a separate sphere, the total surface would be about a factor of two larger than that of the neat aqueous KI solution particle, which should lead to a maximum decrease of the uptake coefficient by a factor of 2 . The uptake coefficient at this mass ratio was even by more than a factor of two lower. This may indicate that a significant part of the droplet surface area was in contact with the excess solid phase and thus effectively reduced the surface area exposed to $\mathrm{O}_{3}$.

Figure 6 represents the ratio of $\gamma_{\text {coated }} / \gamma_{\text {coated }}$ as a function of the carbon chain length for three different mass ratios. While the mass ratio dependence is already contained in Fig. 5a, this plot makes the complex interplay between phase state, coverage, mass transfer properties and carbon chain length strikingly apparent. From Figs. $2 b$ and $3 b$ we note that we form a monolayer at the ESP for a mass ratio of 6,10 and $15 \%$ for $C_{12}, C_{15}$ and $C_{18}$, respectively. Therefore, in Fig. 6, the lowest mass ratio for lauric acid $\left(\mathrm{C}_{12}\right)$ is slightly below the position of the ESP, corresponding to a more dilute monolayer. The uptake coefficient responds slightly to an increase in mass ratio. A similar behavior is

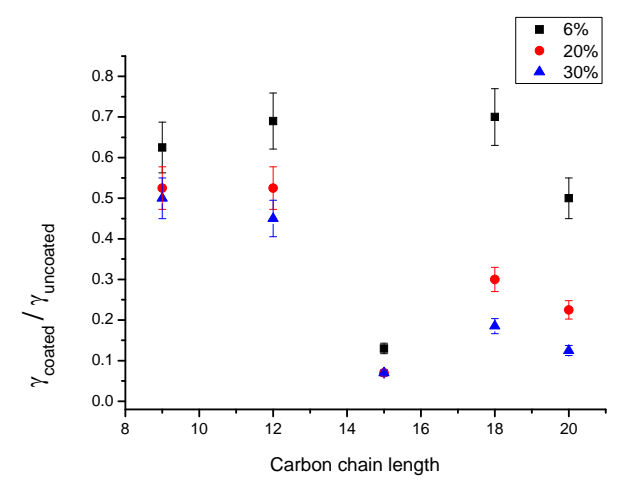

Fig. 6. Ratio $\gamma_{\text {coated }} / \gamma_{\text {uncoated }}$ as a function of the carbon chain length for three different mass ratios of organic (black squares: $6 \%$, red circles: $20 \%$, blue triangles: $30 \%$ ).

observed for the $\mathrm{C}_{9}$ compound. In striking contrast, for $\mathrm{C}_{15}$ we observed a very strong decrease already for a mass ratio of $6 \%$. Increasing the mass ratio to $20 \%$, for which we expect the monolayer at its ESP with already a slight excess fatty acid phase, leads to a further drop of the uptake coefficient. Further increasing the mass ratio to $30 \%$ did not lead to a further change in the uptake coefficient. For $\mathrm{C}_{18}$, with a mass ratio of $6 \%$, the monolayer formed is quite more dilute than expected for the ESP, and the major drop in the uptake coefficient of ozone occurs with increasing the mass ratio to $20 \%$, above the ESP, and a small further drop for the mass ratio increasing to $30 \%$. Although we observe similar behavior for the $\mathrm{C}_{20}$ compound, we note that the model by Seidl returns a negative ESP, which means that it may eventually not spread spontaneously over the aqueous surface. Similar to the $\mathrm{C}_{18}$ case the reduction of the uptake coefficient could be partially explained by the increased surface area of the mixed phase particle. Again, the reduction of the uptake coefficient is more than expected based on the larger surface area due to the excess organic phase. Therefore, the formation of a monolayer also for the $\mathrm{C}_{20}$ may be feasible in spite of the negative ESP estimated by the model of Seidl (2000).

After deconvoluting the observations in Figs. 5a and 6 to take into account the mass fraction for each compound, at which a monolayer at the ESP can be formed, leads to a consistent picture of increasing inhibition of $\mathrm{O}_{3}$ uptake with increasing mass ratio up to the point, where the monolayer exists at its ESP. A further decrease of the uptake coefficient may be related to the increasing surface area of an excess unreactive fatty acid phase. However, the most striking difference between the degree of uptake reduction for monolayers at the ESP among the different compounds is rooted in the different phase states the monolayers exist at the ESP. We therefore also indicate the position of the phase transition from an expanded to a condensed liquid state, $\mathrm{Fj}$, also obtained from the model of Seidl (2000) as open circles in Fig. 5b. It is immediately apparent that when going from 

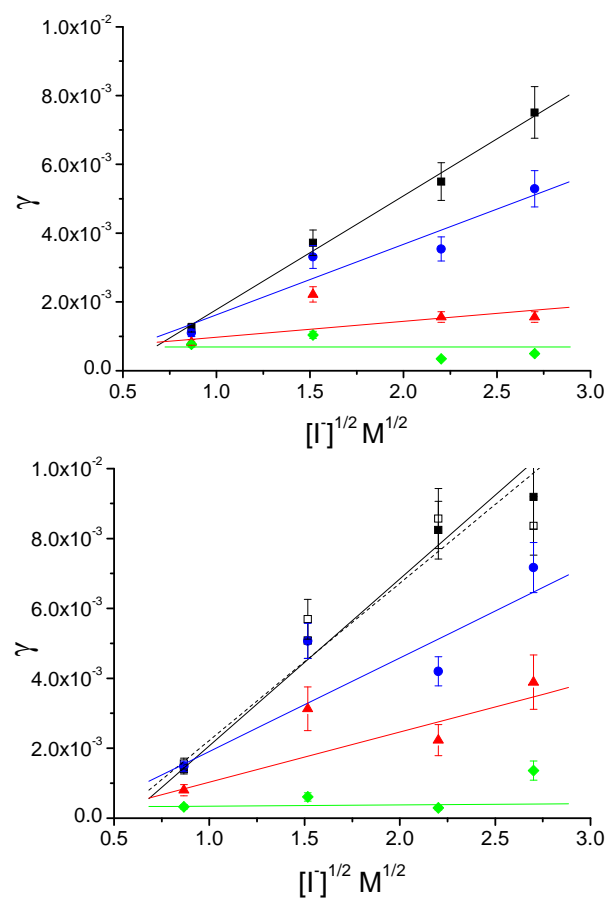

Fig. 7. Plot of the uptake coefficient as a function of the iodide concentration in terms of $\sqrt{\left[I^{-}\right]}$for different mass ratios of surfactant ((a) for $\mathrm{C}_{15}$ and (b) for $\mathrm{C}_{18}$ ). For $\mathrm{C}_{15}$, in (a): black squares: no coating, blue circles: $3 \%$, red triangles: $4 \%$ and green diamonds: $30 \%$. For $\mathrm{C}_{18}$, in (b): black squares: no coating, open black square: $0 \%$ (at $30^{\circ} \mathrm{C}$ in the evaporator), blue circles: $2 \%$, red triangles: $6 \%$ and green diamonds: $37 \%$. The lines are linear fits to the data.

higher to lower area per molecule or from lower to higher mass fraction, the $\mathrm{C}_{15}$ hits this phase transition first. Thus, for $\mathrm{C}_{15}$, the state of the film at the ESP is condensed liquid, which has a substantially higher degree of ordering than in the expanded state, which in turn obviously leads to its increased resistance towards transfer of $\mathrm{O}_{3}$ across the monolayer. In contrast, the $\mathrm{C}_{12}$ remains in its expanded state up to the ESP, associated with an only small effect on $\mathrm{O}_{3}$ uptake. Higher compression would be necessary to bring a $\mathrm{C}_{12}$ monolayer to its condensed liquid state, for which no driving force is available under the conditions of the present experiments. Also for the $\mathrm{C}_{18}$ film, we expect the phase transition to the liquid condensed state just before the ESP, but at substantially higher mass fractions than for the $\mathrm{C}_{15}$. This explains the delayed response of the uptake coefficient to increasing mass fractions for $\mathrm{C}_{18}$ beyond that expected based on the difference in molecular weight alone.

Uptake coefficients obtained for aerosols containing a mixture of sodium chloride and potassium iodide in presence of fatty acids are shown as a function of the iodide concentration in Fig. 7a for the $\mathrm{C}_{15}$ and in Fig. $7 \mathrm{~b}$ for the $\mathrm{C}_{18}$ compound, along with the results of a reference measurement in absence of coating for each salt composition. To calculate the iodide concentrations we used the same procedure as described by Rouvière et al. (2010). For the mixed solution particles, we considered the solute mole fraction of iodide and chloride in the nebulized solution $\left(x_{\mathrm{Cl}^{-}}, x_{\mathrm{I}^{-}}\right)$. Then, by first measuring the size distribution under dry conditions for each experiment, we obtained the dry particle diameter $\left(D_{0}\right)$ and the dry particle volume, from which we deduced the total number of moles (iodide and chloride, $n_{T 0}$ ) in the mixed particles by taking into account the density and the mole fraction of each salt. Under humid conditions, where particles were deliquesced, we obtained a wet diameter and a wet volume $(D, V)$, and we calculated the total concentration of solutes for the mixed aqueous particles $\left(C_{\mathrm{T}}=n_{\mathrm{T} 0} / V\right)$. Finally, to obtain the iodide concentration we applied the mole fraction $\left(x_{\mathrm{Cl}^{-}}, x_{I^{-}}\right)$to this concentration. The uptake coefficients presented in Fig. 7 are time averaged uptake coefficients calculated from the total ozone loss at the maximum residence time. As we have established earlier, $\mathrm{O}_{3}$ uptake is driven by bulk reaction in the particle phase, and thus the uptake coefficient scales linearly with the square root of the iodide concentration (Eq. 3). Note that this linear relation is not granted, if significant depletion of iodide occurs during the course of the residence time in the reactor as discussed in detail with a larger data set by Rouviere et al. (2010). The difference obtained in slope for the two reference cases presented in Fig. 7a and b are within scatter of the experimental data.

From Fig. 5a and b we could determine that we are forming a monolayer at the ESP for $\mathrm{C}_{15}$ and $\mathrm{C}_{18}$ as soon as we obtain a mass ratio of surfactant of 10 and $15 \%$, respectively. From Fig. 7a and b we observed for both FA that the slope of increase of the uptake coefficient with iodide concentration decreases with increasing organic mass fraction. In both cases, for mass ratios of $30 \%$ and above, the uptake coefficient was insensitive to the iodide concentration. The changing slope is a direct result of the increasing contribution of the term $(1 / \beta)$ to overall uptake (Eq. 3). The rate of uptake shifts from being mostly reaction limited in presence of low amounts of organics to phase transfer limited at higher organic loadings. In accordance with the observations made with pure KI particles, this change in kinetic regime occurs at lower mass ratios for the $\mathrm{C}_{15}$ than for the $\mathrm{C}_{18}$ fatty acid. In both cases, for the highest mass ratios we expect a monolayer at its ESP, which is in the condensed liquid state. Since, obviously, the uptake is not influenced by the bulk reactivity $\left(\Gamma_{\mathrm{b}}\right)$ anymore for this case, $\gamma$ can be expressed by $\frac{1}{\gamma}=\frac{1}{\beta}$. To estimate the resistance of the fatty acids for the transfer of $\mathrm{O}_{3}$ at the interface we used the results from figure 7 for the highest mass ratio of surfactant: $\beta_{\mathrm{C}_{15}}=6.8 \times 10^{-4}$ and $\beta_{\mathrm{C}_{18}}=3.3 \times 10^{-4}$. Therefore, in spite of the slightly stronger compression of the $\mathrm{C}_{15} \mathrm{film}$, the resistance $(1 / \beta)$ for $\mathrm{O}_{3}$ to cross this monolayer is about a factor two lower than for the $\mathrm{C}_{18}$ film. This might be related to the structure of these films and the longer chain length of the $\mathrm{C}_{18}$ fatty acid. 
In an attempt to assess the inhibiting effects of mixed component surfactant layers we made a few rather qualitative experiments with $\mathrm{C}_{12} / \mathrm{C}_{15}$ and $\mathrm{C}_{12} / \mathrm{C}_{18}$ mixtures each containing a short and a long chained surfactant. Based on the results presented so far, $\mathrm{C}_{12}$ behaves substantially different than $\mathrm{C}_{15}$ or $\mathrm{C}_{18}$, as it should not be able to form a liquid condensed film under our experimental conditions. Therefore, the intention of these experiments was to assess whether addition of the $\mathrm{C}_{12}$ fatty acid could significantly change the inhibitory effect of the $\mathrm{C}_{15}$ or the $\mathrm{C}_{18}$ monolayers. While Cosman and Bertram (2008) were able to control the composition of two component films, we mixed the two components in the evaporator in the same configuration as for coating the particles with one component alone described above. The amount of fatty acid condensing on the particles is related to its vapor pressure in the evaporator and to the temperature gradient in the condenser tube. The vapor pressure of one of the components in the evaporator should not depend strongly on the presence or not of an additional component in absence of mass transport limitations. We therefore assumed that the relative composition of the coated particles roughly scales with the mass ratios obtained for each component individually. Figure $8 \mathrm{a}$ and $\mathrm{b}$ presents the ratio $\gamma_{\text {mixed film }} / \gamma_{\text {uncoated }}$ for the two individual components $\mathrm{C}_{12}$ and $\mathrm{C}_{15}$ and $\mathrm{C}_{12}$ and $\mathrm{C}_{18}$, respectively, as well as the mixtures thereof, in a format similar to Fig. 6. In Fig. 8, however, we do not use the measured mass ratio of organic but rather the evaporator temperature to categorize different levels of coatings. In Fig. 8a, the addition of some amount of $\mathrm{C}_{15}$ to the $\mathrm{C}_{12}$ in the evaporator leads to a strong change in the reduction of the uptake coefficient and a response more closely to that of the pure $\mathrm{C}_{15}$ case. The relative proportion of $\mathrm{C}_{15}$ to $\mathrm{C}_{12}$ in the evaporator does not strongly affect the results, since the vapor pressure in the evaporator of each component does not depend on the relative composition of the condensed phase. The dominating role of $\mathrm{C}_{15}$ in inhibiting the transfer of $\mathrm{O}_{3}$ in the mixed film is likely because at the same temperature, the mass ratio of a $\mathrm{C}_{15}$ coating is by far higher than that of a $\mathrm{C}_{12}$ coating (Fig. 2b). This is also the case for the mixture between the $\mathrm{C}_{12}$ and the $\mathrm{C}_{18}$, where the mixed coating is likely also dominated by the $\mathrm{C}_{18}$. This would then be consistent with the observed $\mathrm{O}_{3}$ uptake reduction being comparable to the pure $\mathrm{C}_{18}$ case (Fig. 8b), and again with little difference between the two different mixtures in the evaporator.

Therefore, in absence of experiments with a wider range of well defined relative compositions, the only conclusion we can draw from these qualitative experimens is that the addition of a small amount of a surfactant, which is in its expanded state, does not strongly affect the resistance of a concomitantly present condensed liquid monolayer towards the phase transfer of $\mathrm{O}_{3}$.

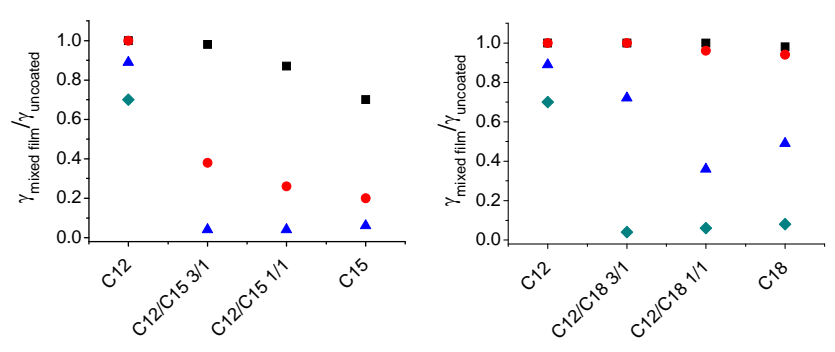

Fig. 8. Evolution of the ratio $\gamma_{\text {mixed film }} / \gamma_{\text {uncoated }}$ for twocomponent coatings (a) $\mathrm{C}_{12} / \mathrm{C}_{15}$ and (b) $\mathrm{C}_{12} / \mathrm{C}_{18}$ at different temperatures of the evaporator $\left(T=40^{\circ} \mathrm{C}\right.$ : black squares, $T=50^{\circ} \mathrm{C}$ : red circles, $T=60^{\circ} \mathrm{C}$ : blue triangles and $T=70^{\circ} \mathrm{C}$ : green diamonds).

\section{General discussion}

Summarizing this discussion, we have observed a substantial reduction in uptake coefficient of $\mathrm{O}_{3}$ to deliquesced $\mathrm{KI}$ aerosol in presence of fatty acid surfactants and that the efficiency of the barrier towards transfer of $\mathrm{O}_{3}$ is strongly related to the phase state of the monolayer formed on the aqueous solution. It seems that only a monolayer in its condensed liquid state is able to inhibit transfer of $\mathrm{O}_{3}$ by more than an order of magnitude. Under such conditions, the monolayer likely exposes a relatively inert aliphatic interface to the adsorbing gases, from which $\mathrm{O}_{3}$ rather desorbs than diffuses across. For the range of fatty acids considered here, $\mathrm{C}_{9}$ to $\mathrm{C}_{20}$, only $\mathrm{C}_{15}, \mathrm{C}_{18}$ and $\mathrm{C}_{20}$ are able to form liquid condensed films if present in excess. Among these, $\mathrm{C}_{15}$, pentadecanoic acid, has the strongest effect, since it forms the densest film at the equilibrium spreading pressure. $\mathrm{C}_{9}$ and $\mathrm{C}_{12}$ fatty acids can only form an expanded film and have therefore only limited ability to inhibit phase transfer of $\mathrm{O}_{3}$.

In general, our results with the rather little soluble $\mathrm{O}_{3}$ are in line with previous studies. Xiong et al. (1998) showed that a $\mathrm{C}_{18}$ coating reduced the hydroscopic growth rate of sulphuric acid aerosol, while a coating of oleic acid (nonlinear and unsaturated) had no effect, likely related to the fact that oleic acid does not form condensed liquid films at pressures, where the saturated straight chain $\mathrm{C}_{18}$ fatty acid does (Seidl, 2000). Similarly, Gilman and Vaida (2006) related the permeability of monolayers to the molecular properties and pressure-area isotherms and demonstrated that the uptake of acetic acid through monolayers of saturated $\mathrm{C}_{18}$ and $\mathrm{C}_{30}$ alcohols into an aqueous phase was strongly reduced. Similar to the case quoted above, uptake of acetic acid was not affected by oleic acid.

Most studies on dinitrogen pentoxide uptake $\left(\mathrm{N}_{2} \mathrm{O}_{5}\right)$ to sulfuric acid, or to $\mathrm{NaCl}$ or sea salt aerosol in presence of organic surfactants have shown an inhibition of the uptake (McNeill et al., 2006; Park et al., 2009; Stewart et al., 2004; Thornton and Abbatt, 2005). More closely comparable to the present study, Cosman and Bertram (2008) studied the 
uptake of $\mathrm{N}_{2} \mathrm{O}_{5}$ on aqueous $\mathrm{H}_{2} \mathrm{SO}_{4}$ solutions coated with 1 or 2 component monolayers. They showed that the reactive uptake coefficient depends on the molecular surface area of the surfactant. They also showed that a small amount of a branched surfactant could affect the overall resistance to the reactive uptake. Since these mixed component films were well defined in composition, these results cannot be directly compared to our qualitative results on mixed films. Some other studies have related the effectiveness of fatty acids to act as barriers for phase transfer to the nature of the head group (polarity), the $\mathrm{pH}$ and the temperature (Barnes, 1997; Johann and Vollhardt, 1999; Latif and Brimblecombe, 2004), parameters which have also a strong impact on the phase state properties of the monolayers.

Concerning atmospheric implications we conclude that the presence of fatty acids in aqueous aerosol particles may have the potential to reduce the uptake of $\mathrm{O}_{3}$. However, it would require strong and persistent sink reactions in the aqueous phase resulting in uptake coefficients larger than $10^{-4}$ until the uptake of $\mathrm{O}_{3}$ would become limited by the permeability of a fatty acid monolayer, for which we determined a probability for transfer and bulk accommodation in the lower $10^{-4}$ range. Smoydzin and von Glasow (2007) present the only detailed model study on the effect of surfactant coatings to the chemistry in the marine boundary layer. They note significant effects on the halogen budgets due to the effect of coatings to reduce phase transfer of the whole suite of $\mathrm{O}_{3}$, halogen and NOy species. Since they represented the coatings by oleic acid only, which has a double bond and is therefore reactive towards $\mathrm{O}_{3}$, their results probably overemphasise the role of coating oxidation by $\mathrm{O}_{3}$, since a major fraction of fatty acids is certainly not reactive towards $\mathrm{O}_{3}$, implicating longer coating lifetimes. Nevertheless oxidation by $\mathrm{OH}$ remains an issue that leads to continuously changing composition of potentially present organic coatings in the real marine boundary layer. Given the complexity of monolayer properties already for the simple fatty acids discussed in this study, it is not yet possible to come up with a comprehensive picture of how organic coatings affect atmospheric chemistry in general. This is due to the very diverse range of compounds with a wide range of ability to partition to the aqueous solution - air interface and with a wide range of monolayer and potentially also more complex layer structure properties.

\section{Conclusions}

The effects of amphiphilic fatty acids on the reaction of ozone with deliquesced potassium iodide aerosol particles were investigated with an aerosol flow tube experiment. This is the first time that this system has been investigated under aerosol conditions. From the previous study in absence of organic coating, we determined an initial uptake coefficient of $\gamma=(1.10 \pm 0.20) \times 10^{-2}$. The presence of a long chain surfactant coating adds a significant resistance to the transfer of $\mathrm{O}_{3}$ to deliquesced aerosol particles, similar to the case of more reactive trace gases. The results showed that, especially for the $\mathrm{C}_{15}-\mathrm{C}_{20}$, amphiphilic surfactants may strongly limit the mass transfer of ozone to the aqueous phase. Through varying the iodide concentration in mixed chloride/iodide particles we could directly determine the resistance exerted at the aqueous surface by two longer chained surfactants: pentadecanoic acid and stearic acid. The outstanding effectiveness of the $\mathrm{C}_{15}$ fatty acid to inhibit the ozone uptake from the gas phase could be explained by the monolayer properties of this fatty acid as compared to the others, specifically by the state and the density of the monolayer formed at the equilibrium spreading pressure. The short chained surfactants $\mathrm{C}_{9}$ and $\mathrm{C}_{12}$ could only form monolayers in the liquid expanded state, known to be not well ordered, and are only slightly hindering ozone uptake. This study highlights the effectiveness of immiscible films of long-chain organics $\left(\mathrm{C}_{15}-\mathrm{C}_{20}\right)$ to have an effect on the mass transport across the air-water interface by acting as a barrier for the transport of volatile species across the interface.

Acknowledgements. This work was supported by the Swiss National Science Foundation (grant no. 200020-109341). We are grateful for the input of our colleague M. Birrer.

Edited by: V. Faye McNeill

\section{References}

Aller, J. Y., Kuznetsova, M. R., Jahns, C. J., and Kemp, P. F.: The sea surface microlayer as a source of viral and bacterial enrichment in marine aerosols, J. Aerosol Sci., 36, 801-812, 2005.

Andrews, E. and Larson, S. M.: Effect of surfactant layers on the size changes of aerosol particles as a function of relative humidity, Environ. Sci. Technol., 27, 857-865, 1993.

Aumann, E. and Tabazadeh, A.: Rate of organic film formation and oxidation on aqueous drops, J. Geophys. Res., 113, D23205. doi:10.1029/2007JD009738, 2008

Badger, C. L., Griffiths, P. T., George, I., Abbatt, J. P. D., and Cox, R. A.: Reactive Uptake of $\mathrm{N}_{2} \mathrm{O}_{5}$ by Aerosol Particles Containing Mixtures of Humic Acid and Ammonium Sulfate, J. Phys. Chem. A, 110, 6986-6994, 2006.

Barnes, G. T.: Permeation through monolayers, Collo. Surf. A, 126, 149-158, 1997.

Bertram, T. H. and Thornton, J. A.: Toward a general parameterization of $\mathrm{N} 2 \mathrm{O} 5$ reactivity on aqueous particles: the competing effects of particle liquid water, nitrate and chloride, Atmos. Chem. Phys., 9, 8351-8363, doi:10.5194/acp-9-8351-2009, 2009.

Burden, D. K., Johnson, A. M., and Nathanson, G. M.: HCl Uptake through Films of Pentanoic Acid and Pentanoic Acid/Hexanol Mixtures at the Surface of Sulfuric Acid, J. Phys. Chem. A, 113, 14131-14140, 2009.

Cavalli, F., Facchini, M. C., Decesari, S., Mircea, M., Emblico, L., Fuzzi, S., Ceburnis, D., Yoon, Y. J., O’Dowd, C. D., Putaud, J. P., and Dell'Acqua, A.: Advances in characterization of size-resolved organic matter in marine aerosol over 
the North Atlantic, J. Geophys. Res.-Atmos., 109, D24215, doi:10.1029/2004JD005137, 2004.

Chan, M. N. and Chan, C. K.: Mass transfer effects in hygroscopic measurements of aerosol particles, Atmos. Chem. Phys., 5, 2703-2712, doi:10.5194/acp-5-2703-2005, 2005.

Cheng, Y., Li, S.-M., Leithead, A., Brickell, P. C., and Leaitch, W. R.: Characterizations of cis-pinonic acid and n-fatty acids on fine aerosols in the Lower Fraser Valley during Pacific 2001 Air Quality Study, Atmos. Environ., 38, 5789-5800, 2004.

Chuang, P. Y.: Measurement of the timescale of hygroscopic growth for atmospheric aerosols, J. Geophys. Res., 108, 4282, doi:10.1029/2002JD002757, 2003.

Cosman, L. M. and Bertram, A. K.: Reactive uptake of N2O5 on aqueous $\mathrm{H}_{2} \mathrm{SO}_{4}$ solutions coated with 1-component and 2component monolayers, J. Phys. Chem. A, 112, 4625-4635, 2008.

Cosman, L. M., Knopf, D. A., and Bertram, A. K.: $\mathrm{N}_{2} \mathrm{O}_{5}$ Reactive Uptake on Aqueous Sulfuric Acid Solutions Coated with Branched and Straight-Chain Insoluble Organic Surfactants, J. Phys. Chem. A, 112, 2386-2396, 2008.

Day, D. A., Takahama, S., Gilardoni, S., and Russell, L. M.: Organic composition of single and submicron particles in different regions of western North America and the eastern Pacific during INTEX-B 2006, Atmos. Chem. Phys., 9, 5433-5446, doi:10.5194/acp-9-5433-2009, 2009.

Donaldson, D. J. and Vaida, V.: The Influence of Organic Films at the Air-Aqueous Boundary on Atmospheric Processes, Chem. Rev., 106, 1445-1461, 2006.

Ellison, G. B., Tuck, A. F., and Vaida, V.: Atmospheric processing of organic aerosols, J. Geophys. Res., 104, 11633-11641, 1999.

Enami, S., Vecitis, C. D., Cheng, J., Hoffmann, M. R., and Colussi, A. J.: Mass spectrometry of interfacial layers during fast aqueous aerosol/ozone gas reactions of atmospheric interest, Chem. Phys. Lett., 455, 316-320, 2008.

Facchini, M. C., Rinaldi, M., Decesari, S., Carbone, C., Finessi, E., Mircea, M., Fuzzi, S., Ceburnis, D., Flanagan, R., Nilsson, E. D., de Leeuw, G., Martino, M., Woeltjen, J., and O'Dowd, C. D.: Primary submicron marine aerosol dominated by insoluble organic colloids and aggregates, Geophys. Res. Lett., 35, L17814, doi:10.1029/2008GL034210, 2008.

Gabler, H. E. and Heumann, K. G.: Determination of Particulate Iodine in Aerosols from Different Regions by Size Fractionating Impactor Sampling and Idms, Int. J. Environ. Anal. Chem., 50, 129-146, 1993.

Gill, P. S., Graedel, T. E., and Weschler, C. J.: Organic Films on Atmospheric Aerosol Particles, Fog Droplets, Cloud Droplets, Raindrops, and Snowflakes, Rev. Geophys., 21, 903-920, 1983.

Gilman, J. B., Tervahattu, H., and Vaida, V.: Interfacial properties of mixed films of long-chain organics at the air-water interface, Atmos. Environ., 40, 6606-6614, 2006.

Gilman, J. B. and Vaida, V.: Permeability of Acetic Acid through Organic Films at the Air-Aqueous Interface, J. Phys. Chem. A, 110, 7581-7587, 2006.

Glass, S. V., Park, S.-C., and Nathanson, G. M.: Evaporation of Water and Uptake of $\mathrm{HCl}$ and $\mathrm{HBr}$ through Hexanol Films at the Surface of Supercooled Sulfuric Acid, J. Phys. Chem. A, 110, 7593-7601, 2006.

Hayase, S., Yabushita, A., Kawasaki, M., Enami, S., Hoffmann, M. R., and Colussi, A. J.: Heterogeneous Reaction of Gaseous
Ozone with Aqueous Iodide in the Presence of Aqueous Organic Species, J. Phys. Chem. A, 114, 6016-6021, 2010.

Hou, X., Zhuang, G., Sun, Y., and An, Z.: Characteristics and sources of polycyclic aromatic hydrocarbons and fatty acids in $\mathrm{PM}_{2.5}$ aerosols in dust season in China, Atmos. Environ., 40, 3251-3262, 2006.

Huang, X.-F., He, L.-Y., Hu, M., and Zhang, Y.-H.: Annual variation of particulate organic compounds in $\mathrm{PM}_{2.5}$ in the urban atmosphere of Beijing, Atmos. Environ., 40, 2449-2458, 2006.

Johann, R. and Vollhardt, D.: Texture features of long-chain fatty acid monolayers at high $\mathrm{pH}$ of the aqueous subphase, Mater. Sci. Eng. C-Biomimetic Supramol. Syst., 8-9, 35-42, 1999.

Kanakidou, M., Seinfeld, J. H., Pandis, S. N., Barnes, I., Dentener, F. J., Facchini, M. C., Van Dingenen, R., Ervens, B., Nenes, A., Nielsen, C. J., Swietlicki, E., Putaud, J. P., Balkanski, Y., Fuzzi, S., Horth, J., Moortgat, G. K., Winterhalter, R., Myhre, C. E. L., Tsigaridis, K., Vignati, E., Stephanou, E. G., and Wilson, J.: Organic aerosol and global climate modelling: a review, Atmos. Chem. Phys., 5, 1053-1123, doi:10.5194/acp-5-1053-2005, 2005.

Kanicky, J. R., Poniatowski, A. F., Mehta, N. R., and Shah, D. O.:Cooperativity among molecules at interfaces in relation to various technological processes: Effect of chain length on the pk(a)of fatty acid salt solutions, Langmuir, 16, 172-177, 2000.

Kanicky, J. R. and Shah, D. O.: Effect of degree, type, and position of unsaturation on the $\mathrm{pk}(\mathrm{a})$ of long-chain fatty acids, J. Colloid Interf. Sci., 256, 201-207, 2002.

Knopf, D. A., Cosman, L. M., Mousavi, P., Mokamati, S., and Bertram, A. K.: A Novel Flow Reactor for Studying Reactions on Liquid Surfaces Coated by Organic Monolayers: Methods, Validation, and Initial Results, J. Phys. Chem. A, 111, 11021-11032, 2007.

Krisch, M. J., D’Auria, R., Brown, M. A., Tobias, D. J., Hemminger, C., Ammann, M., Starr, D. E., and Bluhm, H.: The Effect of an Organic Surfactant on the Liquid-Vapor Interface of an Electrolyte Solution, J. Phys. Chem. C, 111, 13497-13509, 2007.

Kuznetsova, M., Lee, C., and Aller, J.: Characterization of the proteinaceous matter in marine aerosols, Marine Chem., 96, 359377, 2005.

Latif, M. T. and Brimblecombe, P.: Surfactants in Atmospheric Aerosols, Environ. Sci. Technol., 38, 6501-6506, 2004.

Leck, C. and Bigg, E. K.: Source and evolution of the marine aerosol - A new perspective, Geophys. Res. Lett., 32, L19803, doi:10.1029/2005GL023651, 2005.

Liu, Q., Schurter, L. M., Muller, C. E., Aloisio, S., Francisco, J. S., and Margerum, D. W.: Kinetics and Mechanisms of Aqueous Ozone Reactions with Bromide, Sulfite, Hydrogen Sulfite, Iodide, and Nitrite Ions, Inorg. Chem., 40, 4436-4442, 2001.

McNeill, V. F., Patterson, J., Wolfe, G. M., and Thornton, J. A.: The effect of varying levels of surfactant on the reactive uptake of $\mathrm{N}_{2} \mathrm{O}_{5}$ to aqueous aerosol, Atmos. Chem. Phys., 6, 1635-1644, doi:10.5194/acp-6-1635-2006, 2006.

McNeill, V. F., Wolfe, G. M., and Thornton, J. A.: The Oxidation of Oleate in Submicron Aqueous Salt Aerosols: Evidence of a Surface Process, J. Phys. Chem. A, 111, 1073-1083, 2007.

Mochida, M., Kitamori, Y., Kawamura, K., Nojiri, Y., and Suzuki, K.: Fatty acids in the marine atmosphere: Factors governing their concentrations and evaluation of organic films 
on sea-salt particles, J. Geophys. Res.-Atmos., 107, 4325, doi:10.1029/2001JD001278, 2002.

Mochida, M., Umemoto, N., Kawamura, K., Lim, H.-J., and Turpin, B. J.: Bimodal size distributions of various organic acids and fatty acids in the marine atmosphere: Influence of anthropogenic aerosols, Asian dusts, and sea spray off the coast of East Asia, J. Geophys. Res., 112, D15209, doi:10.1029/2006JD007773, 2007.

O'Dowd, C. D., Facchini, M. C., Cavalli, F., Ceburnis, D., Mircea, M., Decesari, S., Fuzzi, S., Yoon, Y. J., and Putaud, J. P.: Biogenically driven organic contribution to marine aerosol, Nature, 431, 676-680, 2004.

Park, S. C., Burden, D. K., and Nathanson, G. M.: The Inhibition of N2O5 Hydrolysis in Sulfuric Acid by 1-Butanol and 1-Hexanol Surfactant Coatings, J. Phys. Chem. A, 111, 2921-2929, 2007.

Park, S. C., Burden, D. K., and Nathanson, G. M.: Surfactant Control of Gas Transport and Reactions at the Surface of Sulfuric Acid, Accounts Chem. Res., 42, 379-387, 2009.

Pio, C., Alves, C., and Duarte, A.: Organic components of aerosols in a forested area of central Greece, Atmos. Environ., 35, 389401, 2001

Pöschl, U., Rudich, Y., and Ammann, M.: Kinetic model framework for aerosol and cloud surface chemistry and gas-particle interactions - Part 1: General equations, parameters, and terminology, Atmos. Chem. Phys., 7, 5989-6023, doi:10.5194/acp-75989-2007, 2007.

Putaud, J. P., Raes, F., Van Dingenen, R., Bruggemann, E., Facchini, M. C., Decesari, S., Fuzzi, S., Gehrig, R., Huglin, C., Laj, P., Lorbeer, G., Maenhaut, W., Mihalopoulos, N., Mulller, K., Querol, X., Rodriguez, S., Schneider, J., Spindler, G., ten Brink, H., Torseth, K., and Wiedensohler, A.: European aerosol phenomenology-2: chemical characteristics of particulate matter at kerbside, urban, rural and background sites in Europe, Atmos. Environ., 38, 2579-2595, 2004.

Riemer, N., Vogel, H., Vogel, B., Anttila, T., Kiendler-Scharr, A., and Mentel, T. F.: Relative importance of organic coatings for the heterogeneous hydrolysis of $\mathrm{N}_{2} \mathrm{O}_{5}$ during summer in Europe, J. Geophys. Res., 114, D17307, doi:10.1029/2008JD011369, , 2009.

Robinson, A. L., Subramanian, R., Donahue, N. M., BernardoBricker, A., and Rogge, W. F.: Source Apportionment of Molecular Markers and Organic Aerosol. 3. Food Cooking Emissions, Environ. Sci. Technol., 40, 7820-7827, 2006.

Rouvière, A., Sosedova, Y., and Ammann, M.: Uptake of ozone to deliquesced $\mathrm{KI}$ and mixed $\mathrm{KI} / \mathrm{NaCl}$ aerosol particles, J. Phys. Chem. A, 114(26), 7085-7093, doi:10.1021/jp103257d, 2010.

Rudich, Y.: Laboratory Perspectives on the Chemical Transformations of Organic Matter in Atmospheric Particles, Chem. Rev., 103, 5097-5124, 2003.

Schauer, J. J., Kleeman, M. J., Cass, G. R., and Simoneit, B. R. T.: Measurement of Emissions from Air Pollution Sources. 4. C1C27 Organic Compounds from Cooking with Seed Oils, Environ. Sci. Technol., 36, 567-575, 2001.

Seidl, W.: Model for a surface film of fatty acids on rain water and aerosol particles, Atmos. Environ., 34, 4917-4932, 2000.

Simoneit, B. R. T. and Mazurek, M. A.: Organic Matter of the Troposphere-II.: Natural Background of biogenic lipid matter in aerosols over the rural western United States, Atmos. Environ., 41, 4-24, 2007.

Smith, G. D., Woods, E., DeForest, C. L., Baer, T., and Miller, R. E.:
Reactive Uptake of Ozone by Oleic Acid Aerosol Particles: Application of Single-Particle Mass Spectrometry to Heterogeneous Reaction Kinetics, J. Phys. Chem. A, 106, 8085-8095, 2002.

Smoydzin, L. and von Glasow, R.: Do organic surface films on sea salt aerosols influence atmospheric chemistry?- A model study, Atmos. Chem. Phys., 7, 5555-5567, doi:10.5194/acp-7-55552007, 2007.

Stemmler, K., Vlasenko, A., Guimbaud, C., and Ammann, M.: The effect of fatty acid surfactants on the uptake of nitric acid to deliquesced $\mathrm{NaCl}$ aerosol, Atmos. Chem. Phys., 8, 5127-5141, doi:10.5194/acp-8-5127-2008, 2008.

Stewart, D. J., Griffiths, P. T., and Cox, R. A.: Reactive uptake coefficients for heterogeneous reaction of $\mathrm{N}_{2} \mathrm{O}_{5}$ with submicron aerosols of $\mathrm{NaCl}$ and natural sea salt, Atmos. Chem. Phys., 4, 1381-1388, doi:10.5194/acp-4-1381-2004, 2004.

Tabazadeh, A.: Organic aggregate formation in aerosols and its impact on the physicochemical properties of atmospheric particles, Atmos. Environ., 39, 5472-5480, 2005.

Tervahattu, H., Hartonen, K., Kerminen, V. M., Kupiainen, K., Aarnio, P., Koskentalo, T., Tuck, A. F., and Vaida, V.: New evidence of an organic layer on marine aerosols, J. Geophys. Res.Atmos., 107, 4053, doi:10.1029/2000JD000282, 2002a.

Tervahattu, H., Juhanoja, J., and Kupiainen, K.: Identification of an organic coating on marine aerosol particles by TOF-SIMS, J. Geophys. Res., 107, 4319, doi:10.1029/2001JD001403, 2002b.

Tervahattu, H., Juhanoja, J., Vaida, V., Tuck, A. F., Niemi, J. V., Kupiainen, K., Kulmala, M., and Vehkamãki, H.: Fatty acids on continental sulfate aerosol particles, J. Geophys. Res., 110, D06207, doi:10.1029/2004JD005400, 2005.

Thornton, J. A., and Abbatt, J. P. D.: $\mathrm{N}_{2} \mathrm{O}_{5}$ Reaction on Submicron Sea Salt Aerosol: Kinetics, Products, and the Effect of Surface Active Organics, J. Phys. Chem. A, 109, 10004-10012, 2005.

Tobias, D. J. and Hemminger, J. C.: Chemistry - Getting specific about specific ion effects, Science, 319, 1197-1198, 2008.

Woods, E. I., Kim, H. S., Wivagg, C. N., Dotson, S. J., Broekhuizen, K. E., and Frohardt, E. F.: Phase Transitions and Surface Morphology of Surfactant-Coated Aerosol Particles, J. Phys. Chem. A, 111, 11013-11020, 2007.

Xiong, J. Q., Zhong, M., Fang, C., Chen, L. C., and Lippmann, M.: Influence of Organic Films on the Hygroscopicity of Ultrafine Sulfuric Acid Aerosol, Environ. Sci. Technol., 32, 3536-3541, 1998.

Zahardis, J. and Petrucci, G. A.: The oleic acid-ozone heterogeneous reaction system: products, kinetics, secondary chemistry, and atmospheric implications of a model system - a review, Atmos. Chem. Phys., 7, 1237-1274, doi:10.5194/acp-7-1237-2007, 2007.

Zhang, Q., Jimenez, J. L., Canagaratna, M. R., Allan, J. D., Coe, H., Ulbrich, I., Alfarra, M. R., Takami, A., Middlebrook, A. M., Sun, Y. L., Dzepina, K., Dunlea, E., Docherty, K., DeCarlo, P. F., Salcedo, D., Onasch, T., Jayne, J. T., Miyoshi, T., Shimono, A., Hatakeyama, S., Takegawa, N., Kondo, Y., Schneider, J., Drewnick, F., Borrmann, S., Weimer, S., Demerjian, K., Williams, P., Bower, K., Bahreini, R., Cottrell, L., Griffin, R. J., Rautiainen, J., Sun, J. Y., Zhang, Y. M., and Worsnop, D. R.: Ubiquity and dominance of oxygenated species in organic aerosols in anthropogenically-influenced Northern Hemisphere midlatitudes, Geophys. Res. Lett., 34, L13801, doi:10.1029/2007GL029979, 2007. 